\title{
Nutrient Deficiencies of Landscape and Field-grown Palms in Florida ${ }^{1}$
}

Timothy K. Broschat ${ }^{2}$

Palms growing in landscapes or field nurseries are subject to a number of potentially serious nutritional deficiencies. Although peninsular Florida soils range from acid and alkaline sands, muck, and marl to limestone, deficiencies of $\mathrm{N}, \mathrm{K}, \mathrm{Mg}, \mathrm{Fe}, \mathrm{Mn}$, and $\mathrm{B}$ are common on palms growing in all of these soil types to some degree.

This document describes the most common nutrient deficiencies of palms in Florida landscapes or field nurseries. See ENH1009 for fertilization recommendations for Florida landscapes and field nurseries.

Most palm nutrient deficiencies can be readily diagnosed using visual symptoms alone. However, in many cases leaf analysis can also be helpful in confirming a diagnosis. Iron and B deficiencies are exceptions, however, as symptoms are often poorly correlated with leaf Fe or B concentrations. When sampling for leaf analysis, select 4 to 6 central leaflets from the youngest fully-expanded leaf. Soil analysis is not particularly useful for diagnosing palm nutrient deficiencies, since palm nutrient symptomology often bears little resemblance to soil nutrient profiles.

\section{Nitrogen (N)}

Although $\mathrm{N}$ is by far the most important limiting element in container production of palms, $\mathrm{N}$ deficiency is rather uncommon on palms growing in native Florida soils. It is the most likely deficiency only on Ptychosperma, Veitchia, Adonidia, and Ravenea spp., and it is uncommon even on these species. Nitrogen deficiency is caused solely by insufficient $\mathrm{N}$ in the soil. Symptoms of $\mathrm{N}$ deficiency appear first on the oldest leaves as a uniform light green coloration (Figure 1). As the deficiency progresses, the entire palm canopy except for the spear leaf will become chlorotic, and growth rate will be reduced sharply. Palms can exist with chronic $\mathrm{N}$ deficiency for a very long time, with leaf size becoming much smaller and trunks tapering to a point as a result.

\section{Potassium (K)}

Potassium deficiency is the most common nutritional disorder of palms, not only in Florida, but throughout the palm-growing world. Symptoms vary among species, but always appear first on the oldest leaves. Older leaflets of some palms such as

1. This document is ENH1018, one of a series of the Environmental Horticulture Department, Florida Cooperative Extension Service, Institute of Food and Agricultural Sciences, University of Florida. Original publication date September 2005. Visit the EDIS Web Site at http://edis.ifas.ufl.edu.

2. Timothy K. Broschat is Professor, Environmental Horticuture Department, Fort Lauderdale Research and Education Center, Institute of Food and Agricultural Sciences, University of Florida, Fort Lauderdale, FL 33314

The Institute of Food and Agricultural Sciences (IFAS) is an Equal Opportunity Institution authorized to provide research, educational information and other services only to individuals and institutions that function with non-discrimination with respect to race, creed, color, religion, age, disability, sex, sexual orientation, marital status, national origin, political opinions or affiliations. U.S. Department of Agriculture, Cooperative Extension Service, University of Florida, IFAS, Florida A. \& M. University Cooperative Extension Program, and Boards of County Commissioners Cooperating. Larry Arrington, Dean 


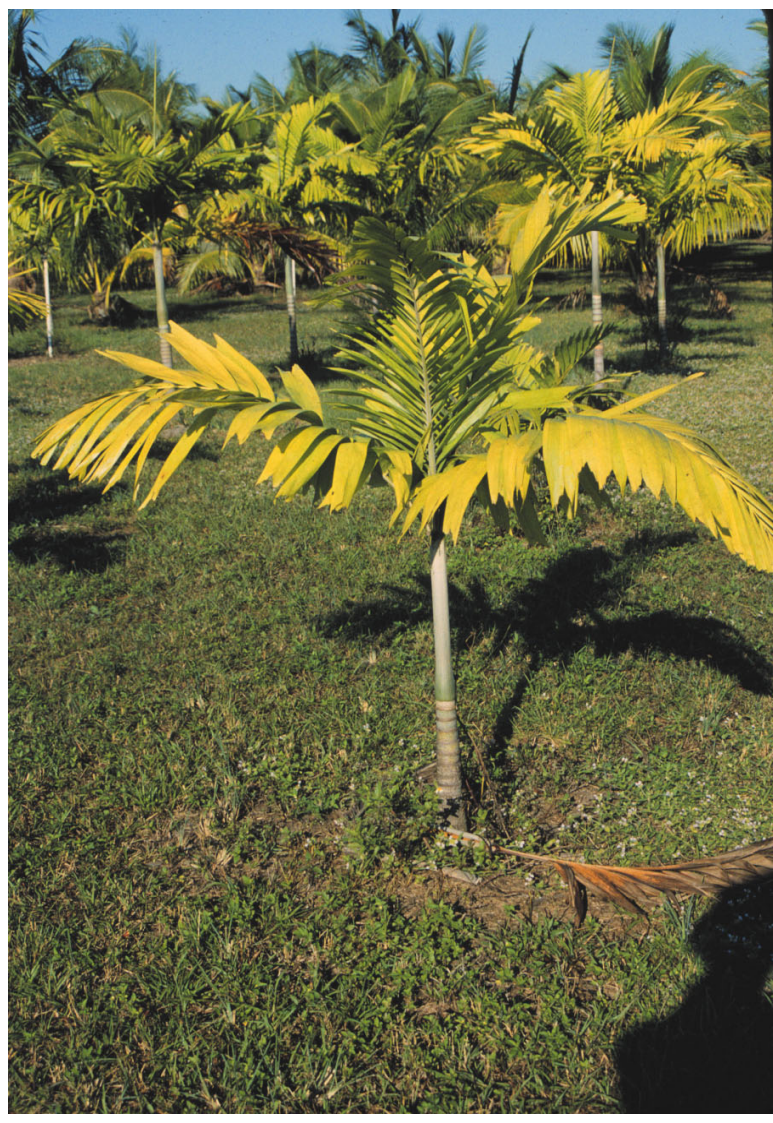

Figure 1. Nitrogen deficiency in Ptychosperma elegans (solitaire palm) showing uniform chlorosis of the older leaves. Credits: T.K. Broschat

Dictyosperma album (hurricane palm) are mottled with yellowish spots that are translucent when viewed from below (Figure 2). In other palms such as Dypsis cabadae (cabada palm), Howea spp. (kentia palms), and Roystonea spp. (royal palms), symptoms appear on older leaves as marginal or tip necrosis with little or no yellowish spotting present (Figure 3). The leaflets in Roystonea, Dypsis, and other pinnate-leaved species showing marginal or tip necrosis often appear withered and frizzled.

\section{In fan palms such as Livistona chinensis} (Chinese fan palm), Corypha spp. (talipot palm), Washingtonia spp. (Washington palms), and Bismarckia nobilis (Bismarck palm), necrosis is not marginal, but is confined largely to tips of the leaflets (Figures 4 and 5). In Phoenix roebelenii (pygmy date palm), the distal parts of the oldest leaves are typically orange with leaflet tips becoming necrotic (Figure 6). The rachis of the leaves usually remains green, however, and the orange and green are not sharply delimited as with $\mathrm{Mg}$ deficiency. This

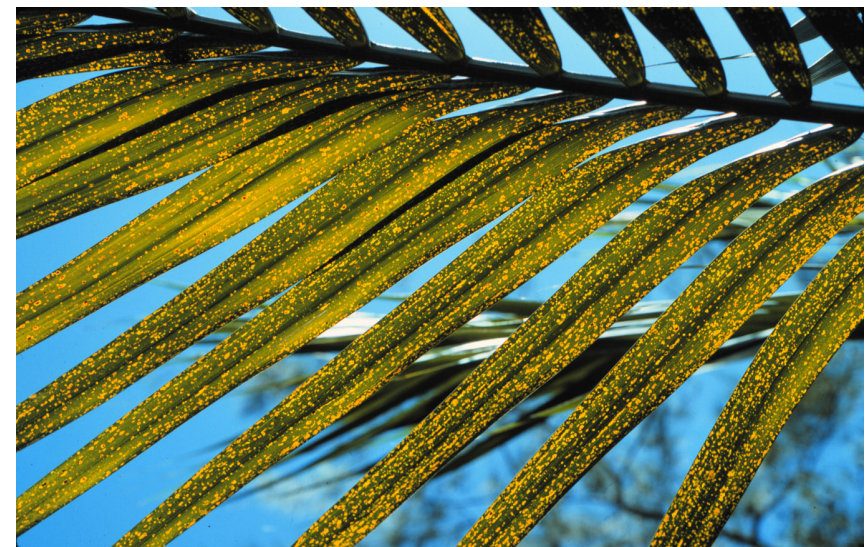

Figure 2. Potassium deficient older leaf of Dictyosperma album (hurricane palm) showing translucent yellow-orange spotting.

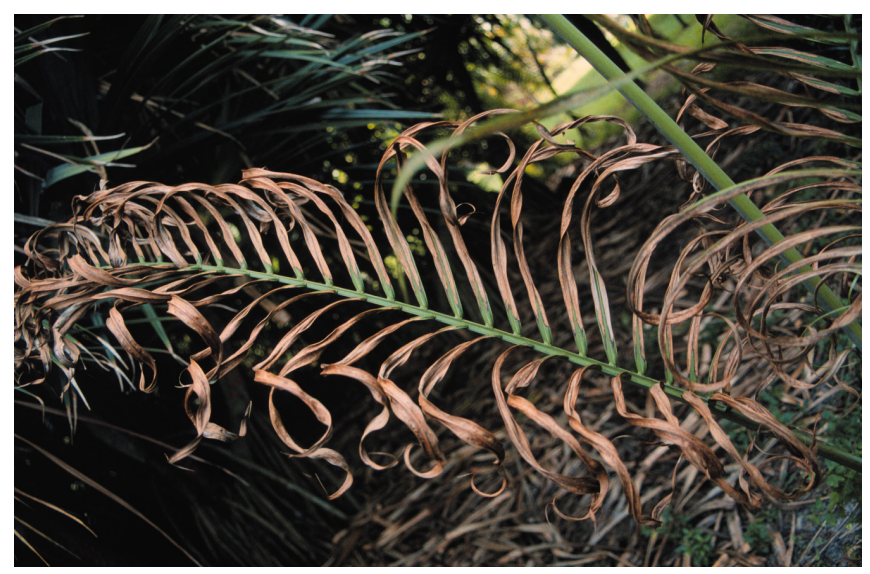

Figure 3. Potassium-deficient older leaf of Dypsis cabadae showing leaflet tip necrosis, but no spotting. Credits: T.K.Broschat

pattern of discoloration holds for most palm species that show discoloration as a symptom. In $P$. canariensis (Canary Island date palm), leaflets show fine (1-2 mm) necrotic and translucent yellow spotting and extensive tip necrosis. These necrotic leaflet tips in most Phoenix spp. are brittle and often break off, leaving the margins of affected leaves irregular.

In Caryota spp. and Arenga spp., chlorotic mottling is minimal or non-existent, but early symptoms appear as irregular necrotic spotting within the leaflets (Figures 7 and 8). In most other palms, including Cocos nucifera (coconut palm), Elaeis guineensis (African oil palm), Dypsis lutescens (areca palm), Chamaerops humilis (European fan palm), Hyophorbe verschafeltii (spindle palm), and others, early symptoms appear as translucent yellow 


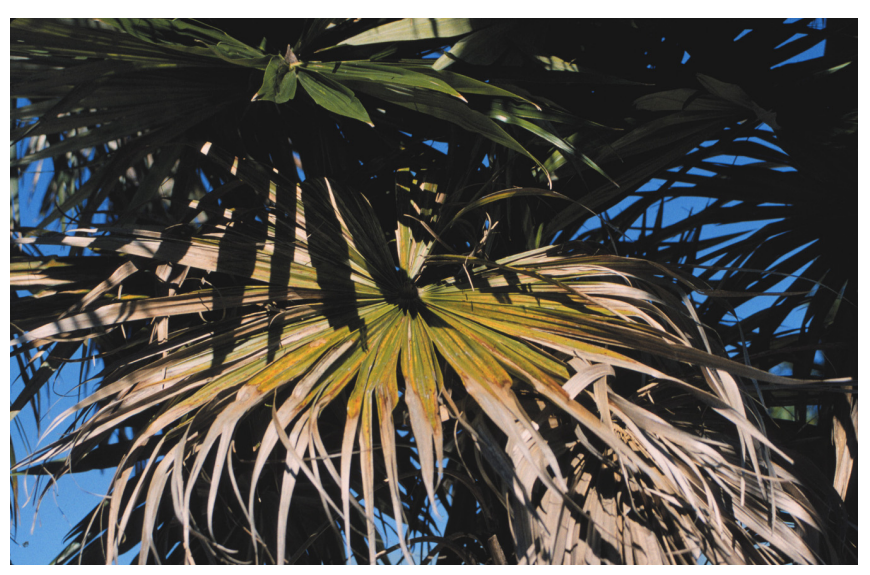

Figure 4. Potassium deficiency in Livistona chinensis showing leaf discoloration and tip necrosis. Credits: T.K. Broschat

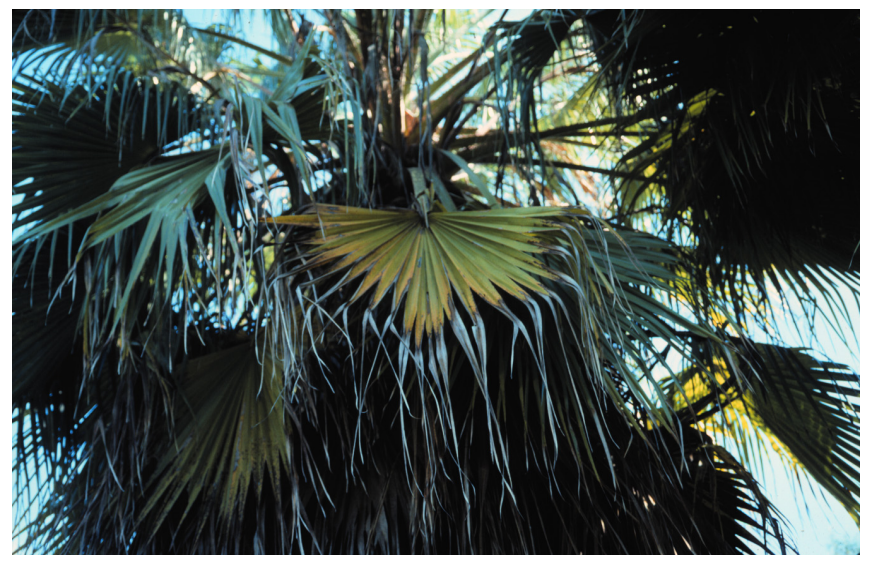

Figure 5.

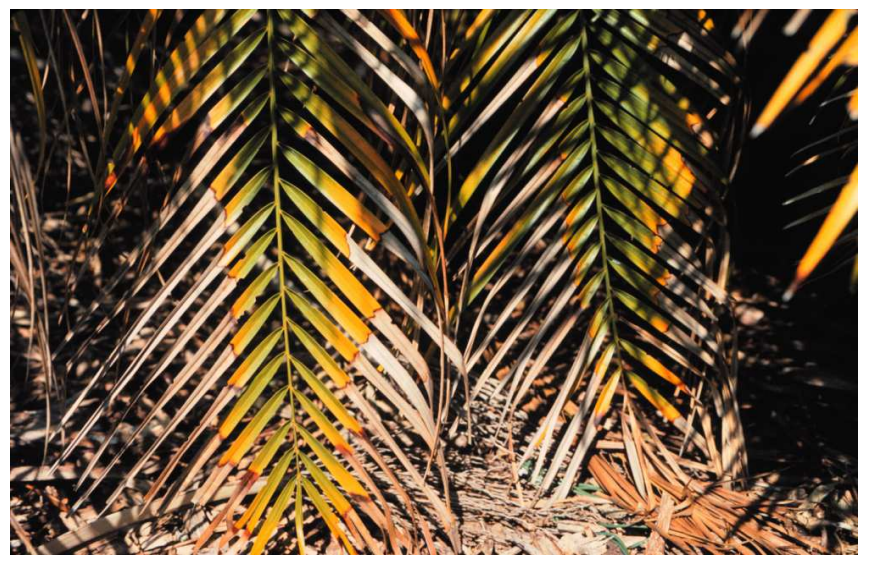

Figure 6. Potassium deficiency in Phoenix roebelenii showing leaf discoloration and tip necrosis. Credits: T.K. Broschat

or orange spotting on the leaflets and may be accompanied by necrotic spotting as well.

As the deficiency progresses, marginal and tip necrosis will also be present (Figure 9). The most severely affected leaves or leaflets will be completely

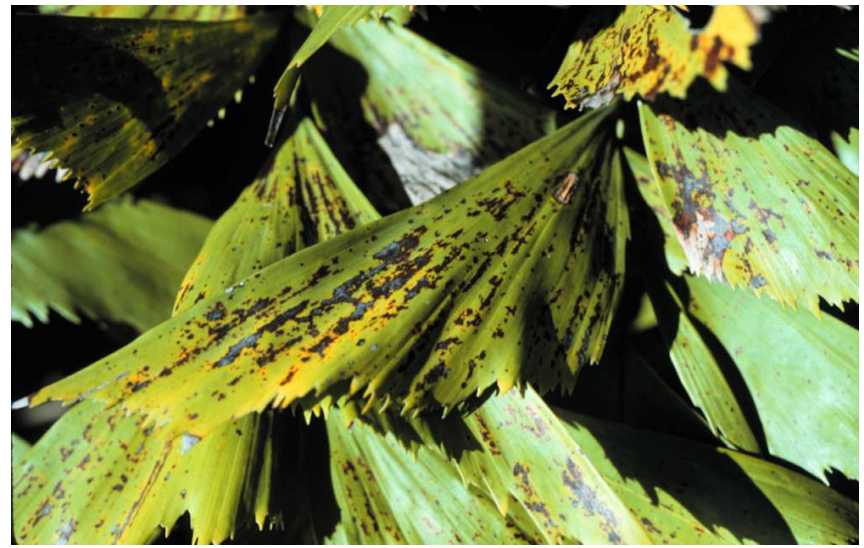

Figure 7. Potassium-deficient older leaves of Caryota mitis (clustering fishtail palm). Credits: T.K. Broschat

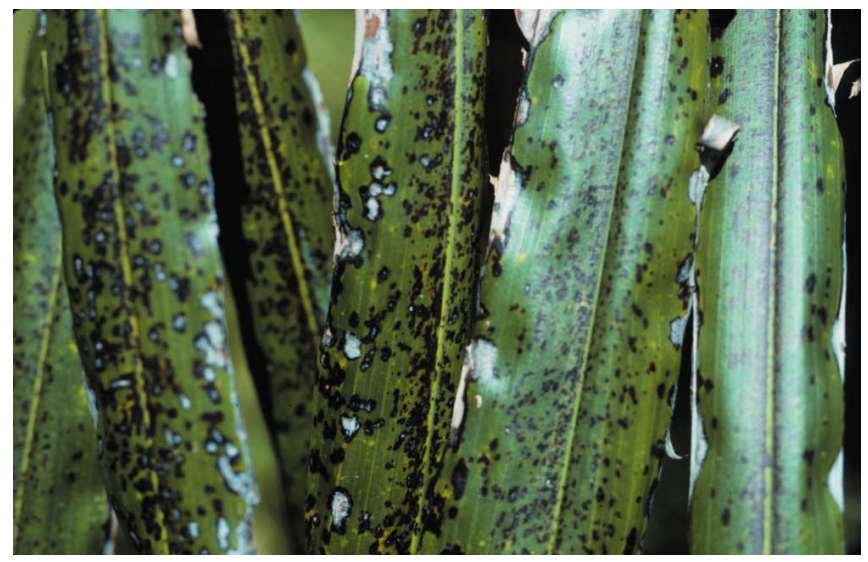

Figure 8. Potassium-deficient older leaf of Arenga tremula showing extensive necrotic spotting and margins. Credits: T.K. Broschat

necrotic and frizzled except for the base of the leaf, leaflet bases, and the rachis. Symptoms decrease in severity from tip to base of a single leaf and from old to new leaves within the canopy (Figures 9 and 10). In severe cases, the entire canopy will consist of a reduced number of leaves, all of which will be chlorotic, frizzled, and stunted (Figure 11). The trunk will begin to taper (pencil-pointing) and death of the palm often follows.

Potassium deficiency is generally caused by insufficient $\mathrm{K}$ in the soil, but is exacerbated by high $\mathrm{N}$ fertilization. Since most Florida soils have very low cation exchange capacities, $\mathrm{K}$ is readily leached out of the root zone by heavy rainfall or irrigation.

\section{Magnesium (Mg)}

Magnesium deficiency is the most common deficiency only on Phoenix canariensis growing in Florida landscapes or field nurseries. In most other 


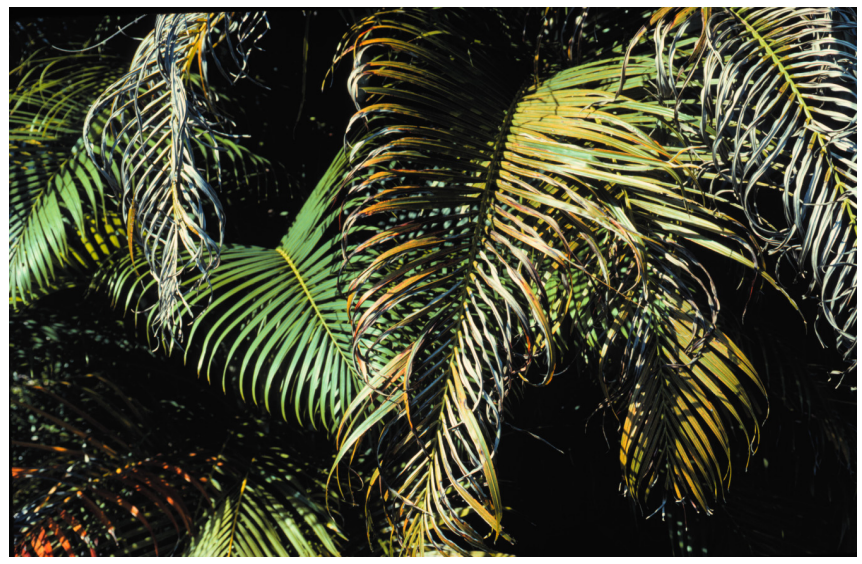

Figure 9. Potassium deficiency on Dypsis lutescens showing discoloration towards the leaf base, but extensive necrosis towards the leaf tips. Credits: T.K. Broschat

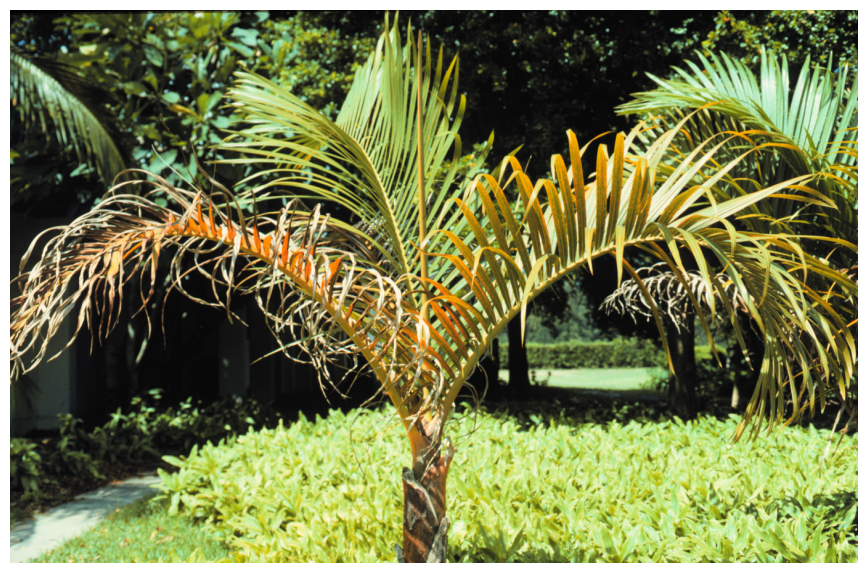

Figure 10. Potassium-deficient Hyophorbe verschafeltii showing progression of symptoms from oldest to youngest leaves. Credits: T.K. Broschat

species of palms, it occurs primarily as a result of improper fertilization. Magnesium deficiency is caused by insufficient $\mathrm{Mg}$ in the soil. Magnesium is readily leached from sandy and other soils having little cation exchange capacity. High levels of $\mathrm{K}$ or $\mathrm{Ca}$ in the soil can also induce or exacerbate $\mathrm{Mg}$ deficiencies.

Symptoms of Mg-deficient palms occur on the oldest leaves as broad chlorotic bands along the margins with the central portion of the leaves remaining distinctly green (Figures 12 and 13). In severe cases, only the rachis and adjacent portions of the leaflets remain green on the oldest leaves, but younger leaves show progressively wider bands of green along the centers of leaves. In Phoenix spp., leaflet tips on the oldest leaves may be necrotic, but this necrosis is due to $\mathrm{K}$ deficiency superimposed on Mg-deficient leaves. In palmate-leaved species with

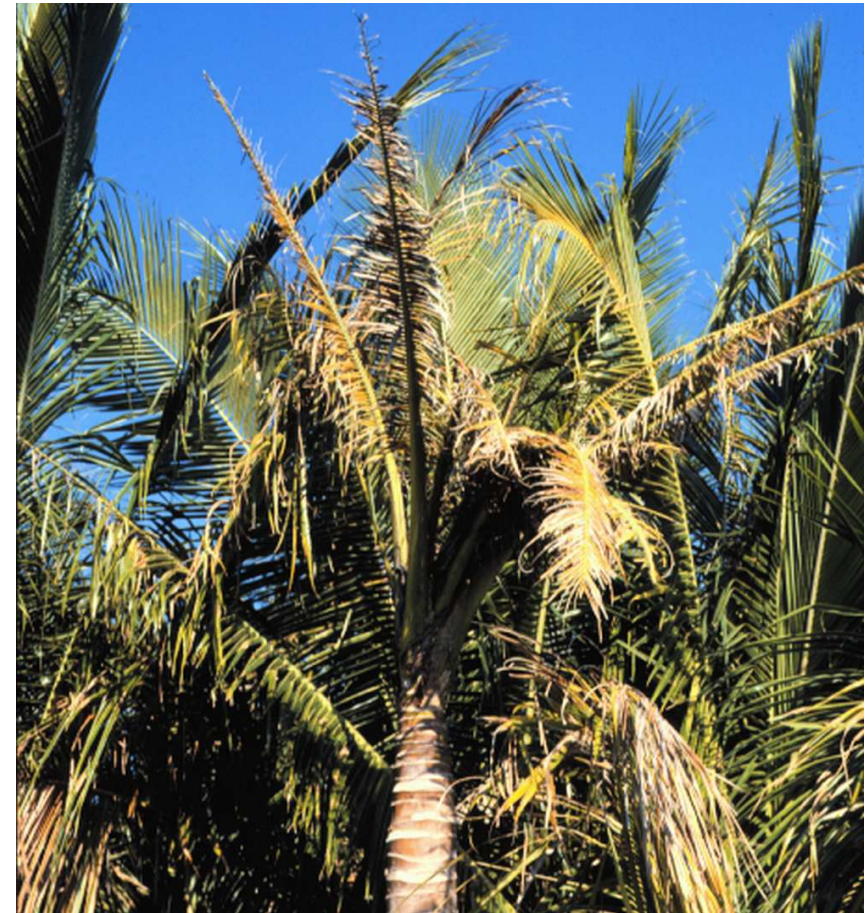

Figure 11. Late stage potassium deficiency in Cocos nucifera showing small chlorotic and necrotic new leaves and tapering of the trunk. This palm died shortly after this photo was taken. Credits: T.K. Broschat

deeply dissected leaves, the chlorosis may appear as broad yellow bands along the margins of individual leaflets (Figure 14). Magnesium deficiency is never fatal in palms.

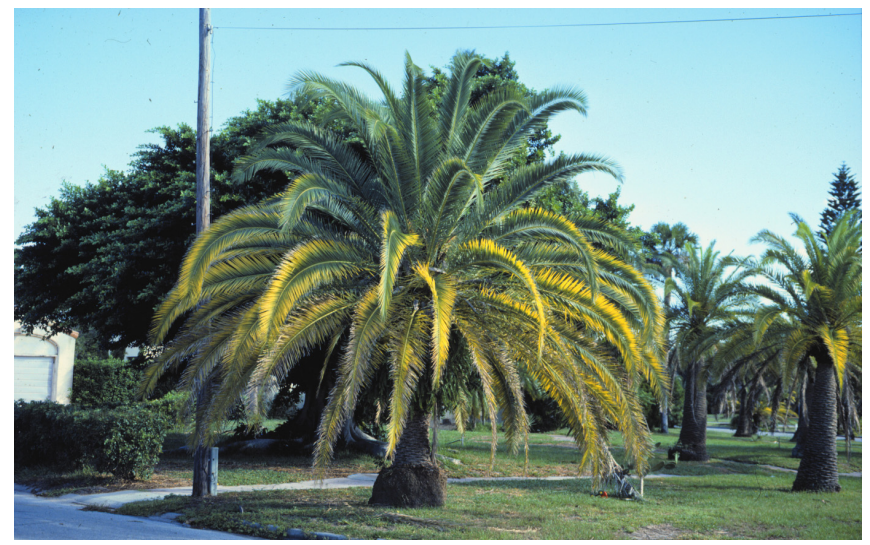

Figure 12. Magnesium deficiency in Phoenix canariensis showing broad yellow bands along the margins of the oldest leaves. Credits: T.K. Broschat

\section{Manganese (Mn)}

Manganese deficiency occurs in a wide range of palm species. It is caused by insufficient $\mathrm{Mn}$ in the soil or by high soil $\mathrm{pH}$, which greatly reduces $\mathrm{Mn}$ availability. In soils where $\mathrm{Mn}$ is marginally 


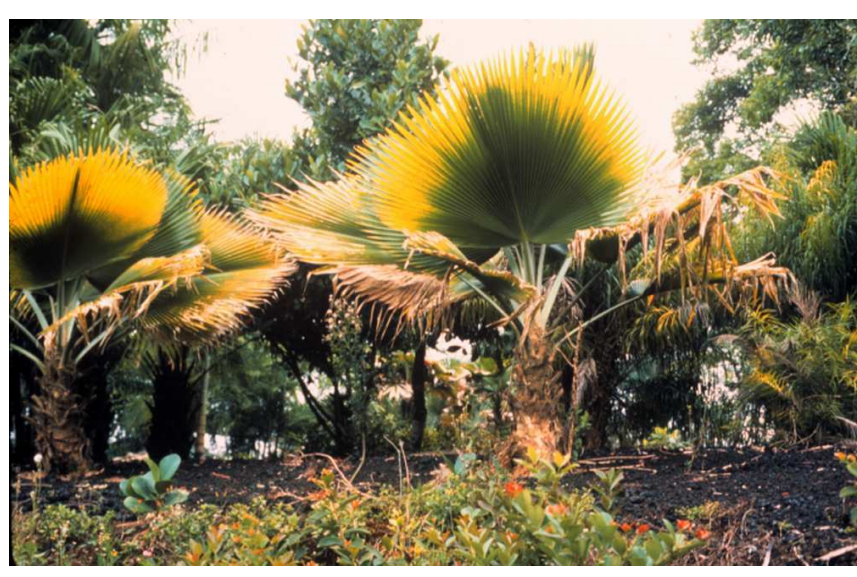

Figure 13. Severe Mg deficiency in Pritchardia sp. showing broad yellow bands around the periphery of the oldest leaves. Credits: T.K. Broschat

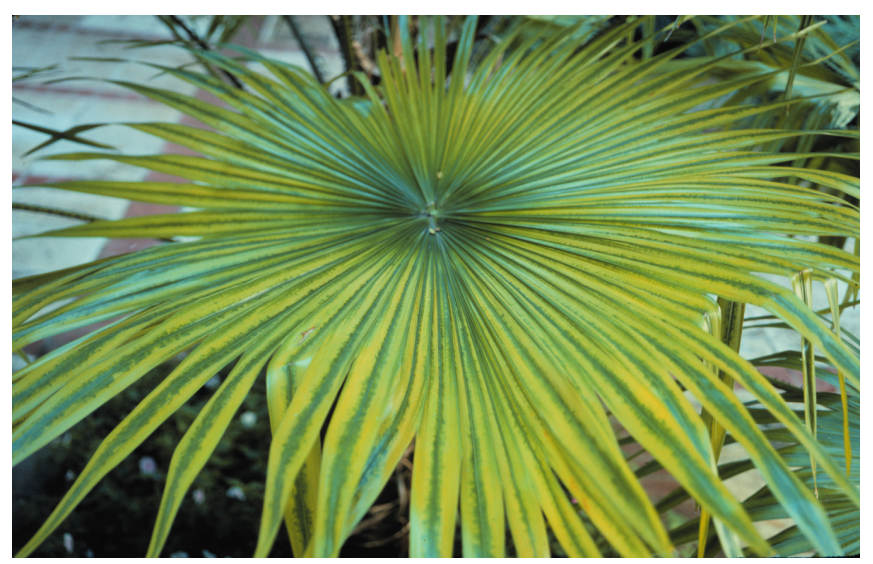

Figure 14. Magnesium-deficient older leaf of Livistona rotundifolia showing yellow bands around the margins of individual leaflets. Credits: T.K. Broschat

sufficient, cold soil temperatures may cause temporary Mn deficiency by reducing root activity levels. This is particularly common on Cocos nucifera in Florida. Composted sewage sludge and manure products have also been shown strongly bind Mn when used as fertilizers or as soil amendments for palms (Figure 21).

Symptoms of Mn deficiency occur on the newest leaves, which emerge chlorotic with longitudinal necrotic streaks (Figures 15 and 16). As the deficiency progresses, newly emerging leaflets appear necrotic and withered on all but basal portions of the leaflets. This withering results in a curling of the leaflets about the rachis giving the leaf a frizzled appearance ("frizzletop") (Figures 17-19). Within a single leaf, Mn deficiency symptoms are most severe at the base of the leaf and are less so or nonexistent towards the tip (Figure 20). On new leaves of Mn-deficient Cocos nucifera, necrotic leaflet tips fall off and the leaf has a singed appearance (Figure 21). In severely Mn-deficient palms, growth stops and newly emerging leaves consist solely of *Figure 22). Death of the meristem usually follows.

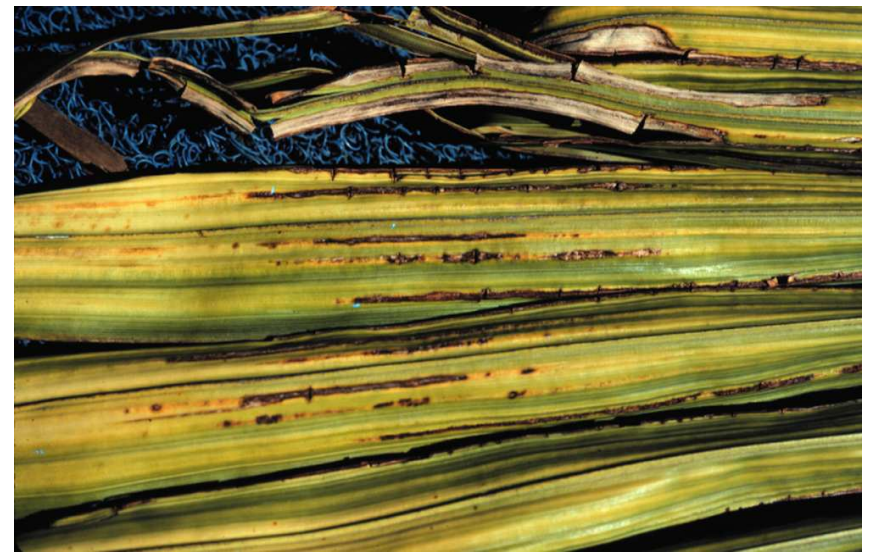

Figure 15. New leaf of Mn-deficient Archontophoenix alexandrae (Alexandra palm)showing interveinal necrotic streaking. Credits: T.K. Broschat

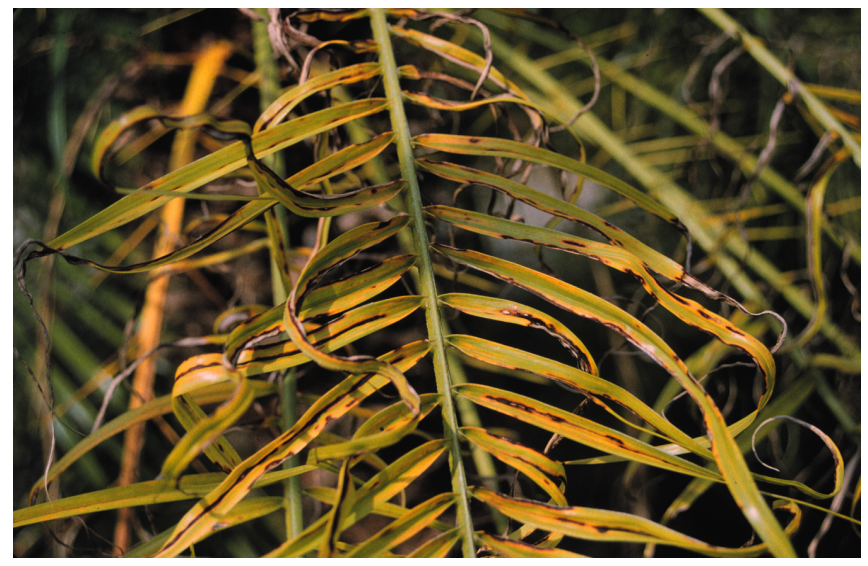

Figure 16. Manganese-deficient new leaf of Phoenix roebelenii showing longitudinal necrotic streaking. Credits: T.K. Broschat

\section{Iron (Fe)}

Iron deficiency is not nearly so common on landscape or field-grown palms as it is in broadleaved plants growing in similar sites. Unlike broadleaved plants, Fe deficiency in palms is usually not caused by a lack of Fe in the soil, but rather by factors that reduce root respiration and therefore active uptake of Fe. These factors include poor soil aeration and planting palms too deeply. Root injury from root rots that typically follow root suffocation will similarly be expressed above ground as Fe 


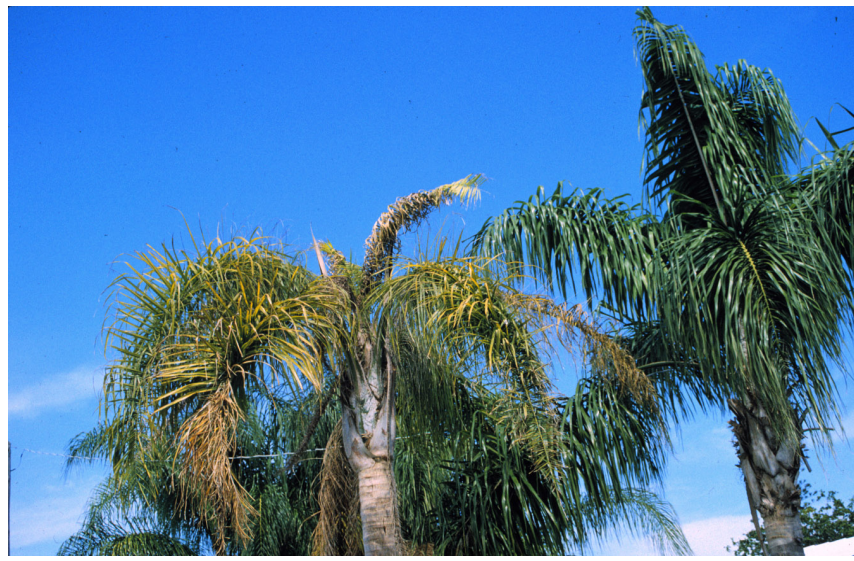

Figure 17. Manganese-deficient Syagrus romanzoffiana on left showing frizzled new leaves, but normal length older leaves. Credits: T.K. Broschat

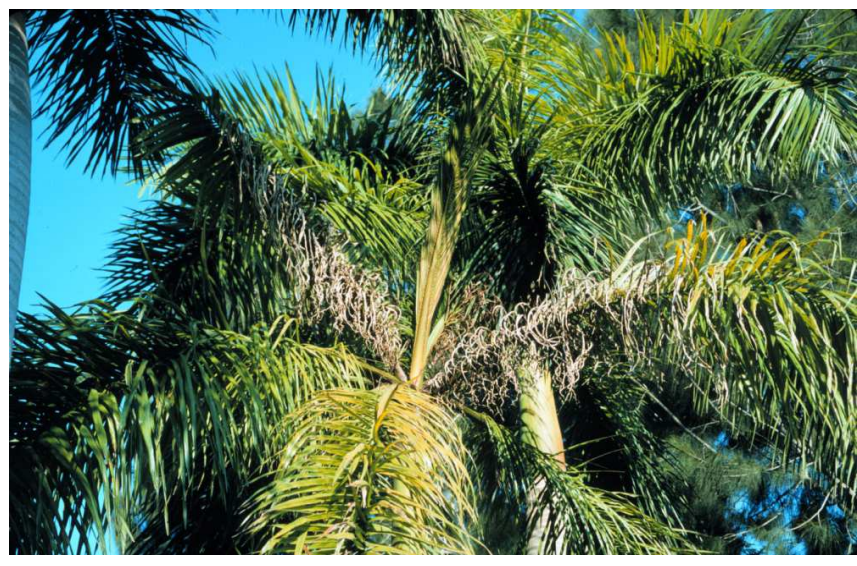

Figure 18. Manganese deficiency in Roystonea regia showing small frizzled new leaves, but full-sized older leaves. Credits: T.K. Broschat

deficiency, since the root surface area available for interception and uptake of Fe will be greatly reduced in root rotted palms. High soil $\mathrm{pH}$ is the most common cause of Fe deficiency in broadleaf trees and shrubs, but in palms it usually does not cause $\mathrm{Fe}$ deficiencies. Excessive uptake of other nutrient ions such as ammonium, phosphate, manganese, zinc, copper, and other heavy metals often results in $\mathrm{Fe}$ deficiency symptoms being expressed.

Iron deficiency appears as interveinal or uniform chlorosis of the newest leaves (Figure 23). Older leaves remain green. In severely Fe-deficient palms, new leaflets may have necrotic tips, growth will be stunted, and the meristem or bud may eventually die (Figure 24). Early symptoms in Syagrus romanzoffiana (queen palm), Rhapis spp. (lady palms), and some Licuala spp. may appear as

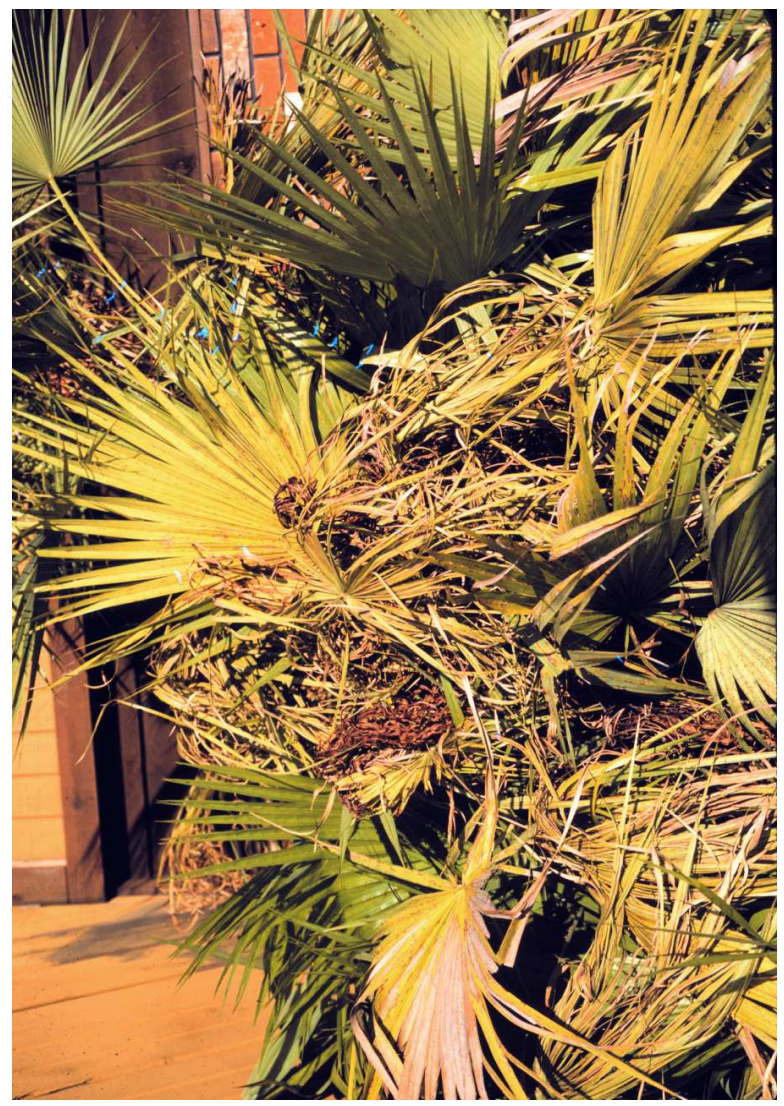

Figure 19. Manganese deficiency or "frizzletop" in Acoelorrhaphe wrightii (paurotis palm). Credits: T.K. Broschat

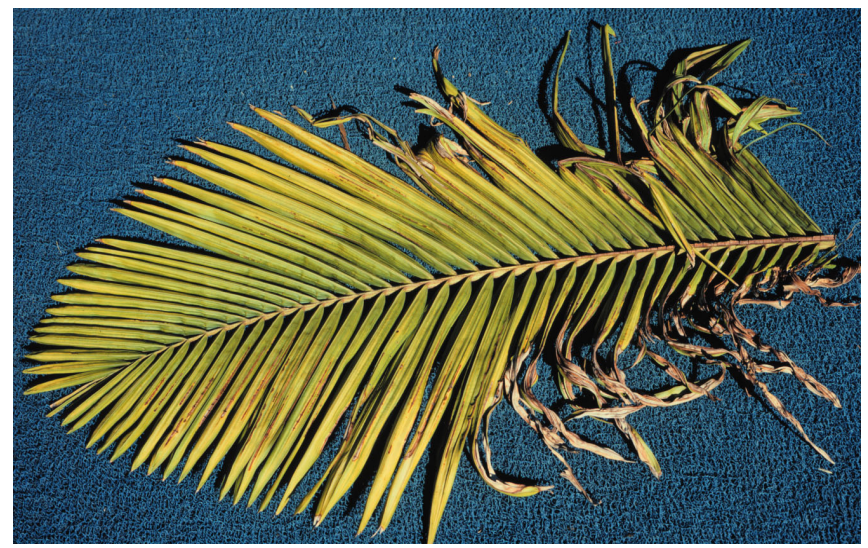

Figure 20. Manganese-deficient new leaf of Archontophoenix alexandrae showing progression of symptoms from leaf tip to leaf base. Credits: T.K. Broschat

chlorotic new leaves covered with green spots about 1/8 inch in diameter (Figure 25).

\section{Boron (B)}

Boron deficiency has become an increasingly important problem on landscape and field-grown palms in recent years. Boron deficiency is caused by 


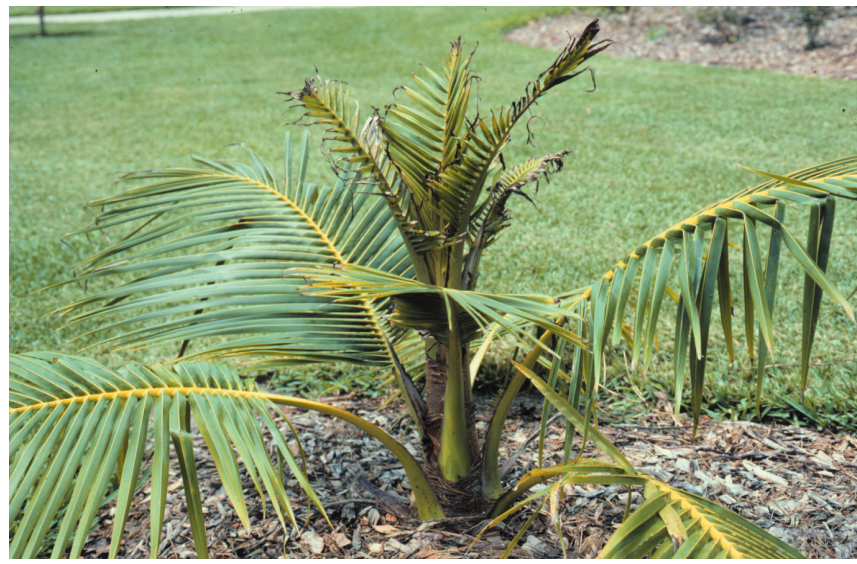

Figure 21. Manganese deficiency in Cocos nucifera caused by amending the backfill with composted sewage sludge. Credits: T.K. Broschat

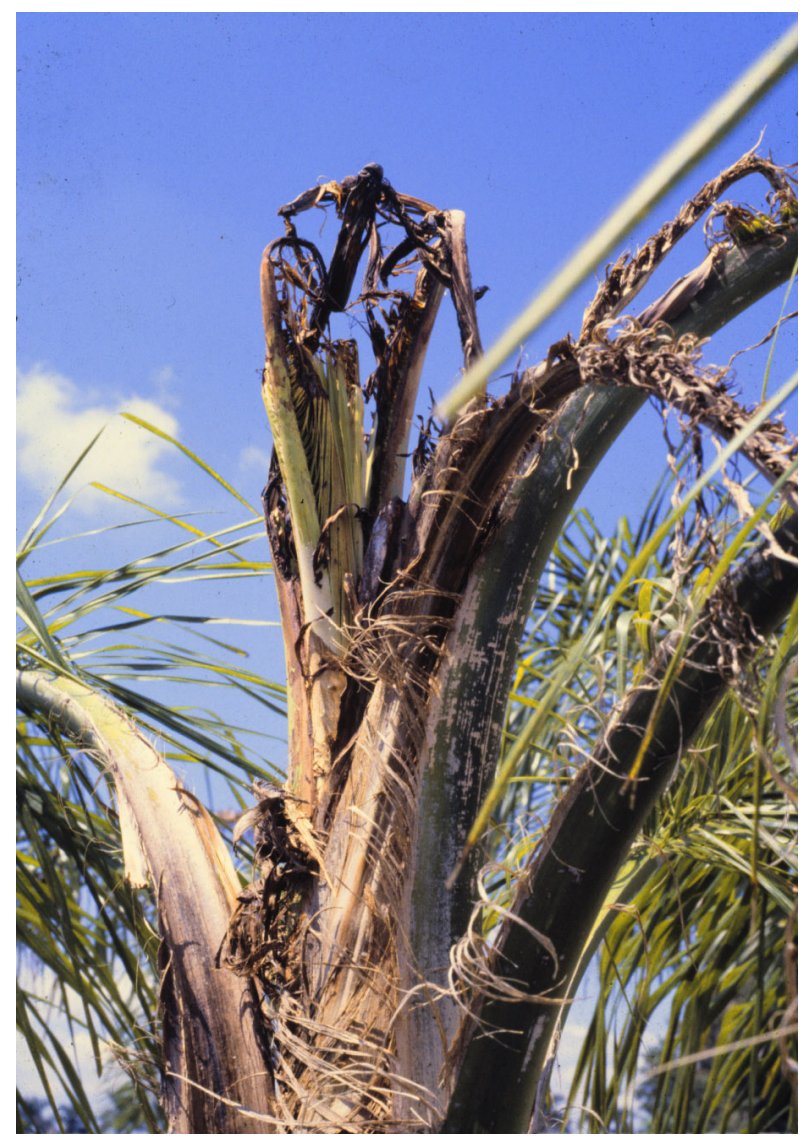

Figure 22. Severe Mn deficiency on Syagrus romanzoffiana showing only necrotic petiole stubs emerging. This palm died shortly after this photo was taken. Credits: T.K. Broschat

insufficient B in the soil. Boron is readily leached through most soils, with a single heavy rain event temporarily leaching most available B out of the root zone. When this leaching stops, B released from decomposing organic matter will again provide adequate $\mathrm{B}$ for normal palm growth in most cases.

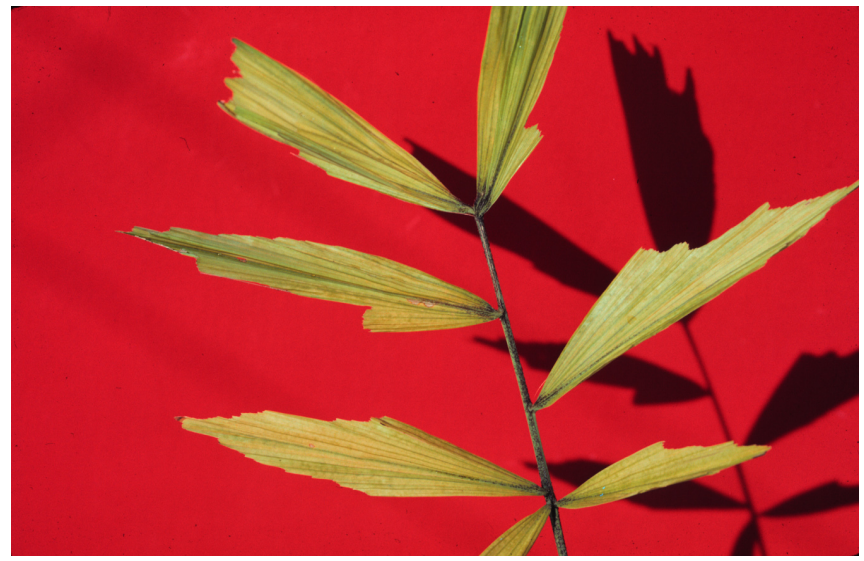

Figure 23. Iron-deficient new leaf of Caryota mitis. Credits: T.K. Broschat

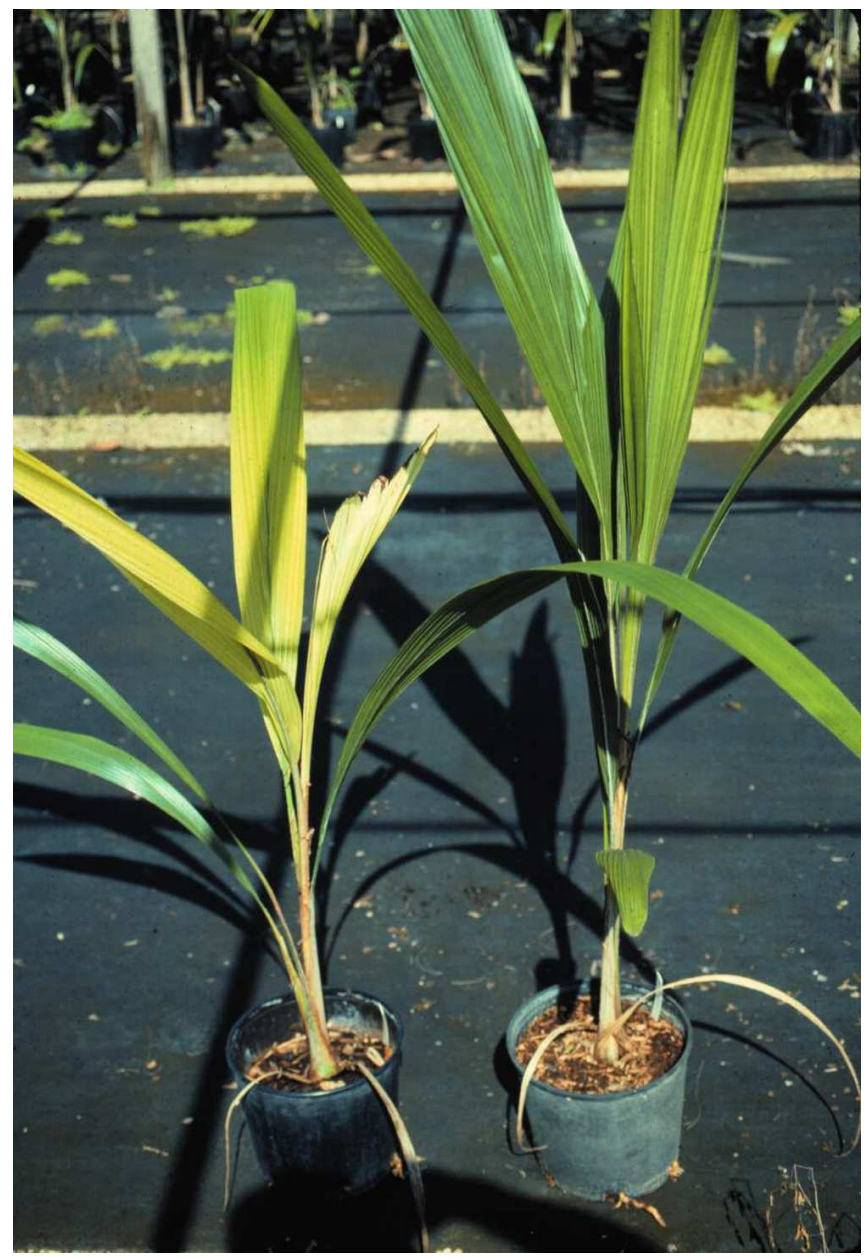

Figure 24. Severely Fe-deficient Syagrus romanzoffiana seedling on the left showing severe chlorosis and leaf tip necrosis. Credits: T.K. Broschat

Boron deficiency causes a wide array of symptoms, not only among species of palms, but also within a single species. Symptoms always occur on newly emerging leaves, but remain visible on these 


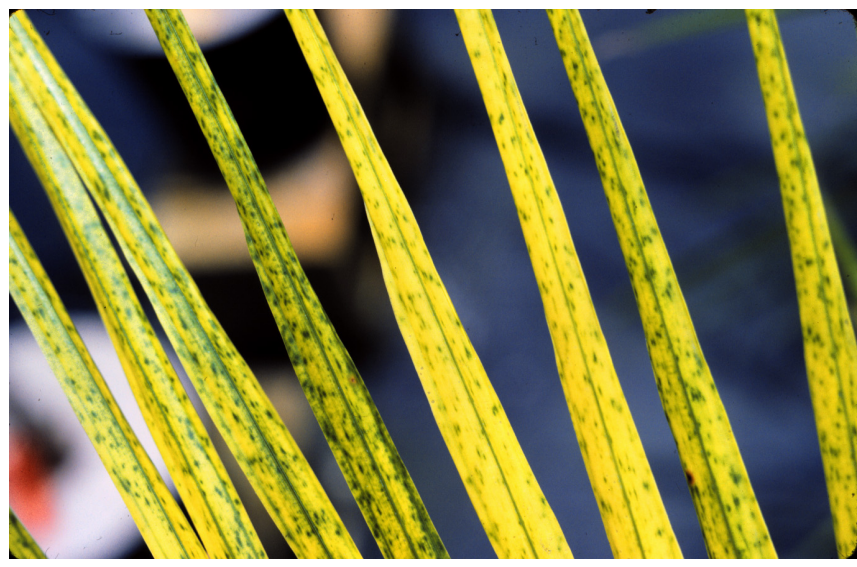

Figure 25. Iron-deficient new leaf of Syagrus romanzoffiana showing green spotting on chlorotic background. Credits: T.K. Broschat

leaves as they mature and are replaced by younger leaves.

One of the earliest symptoms of B deficiency on Dypsis lutescens and Syagrus romanzoffiana is transverse translucent streaking on the leaflets. In many species including Cocos nucifera, Elaeis guineensis, and $S$. romanzoffiana, mild B deficiency is manifested as sharply bent leaflet tips, commonly called "hookleaf" (Figure 26). These sharp leaflet hooks are quire rigid and cannot be straightened out without tearing the leaflets. In some species, these "hooks" drop off.

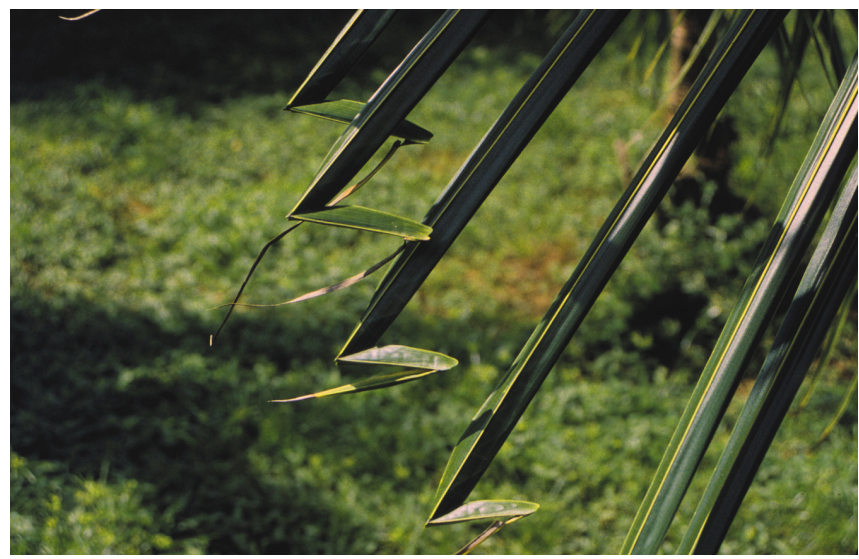

Figure 26. Hookleaf in Cocos nucifera, a symptom of mild B deficiency. Credits: T.K. Broschat

Another symptom associated with chronic B deficiency in $S$. romanzoffiana is the production of weak, narrow leaflets towards the tips of newly emerging leaves. These leaflets often drop off, leaving the rachis tip devoid of leaflets (Figure 27 and 28).

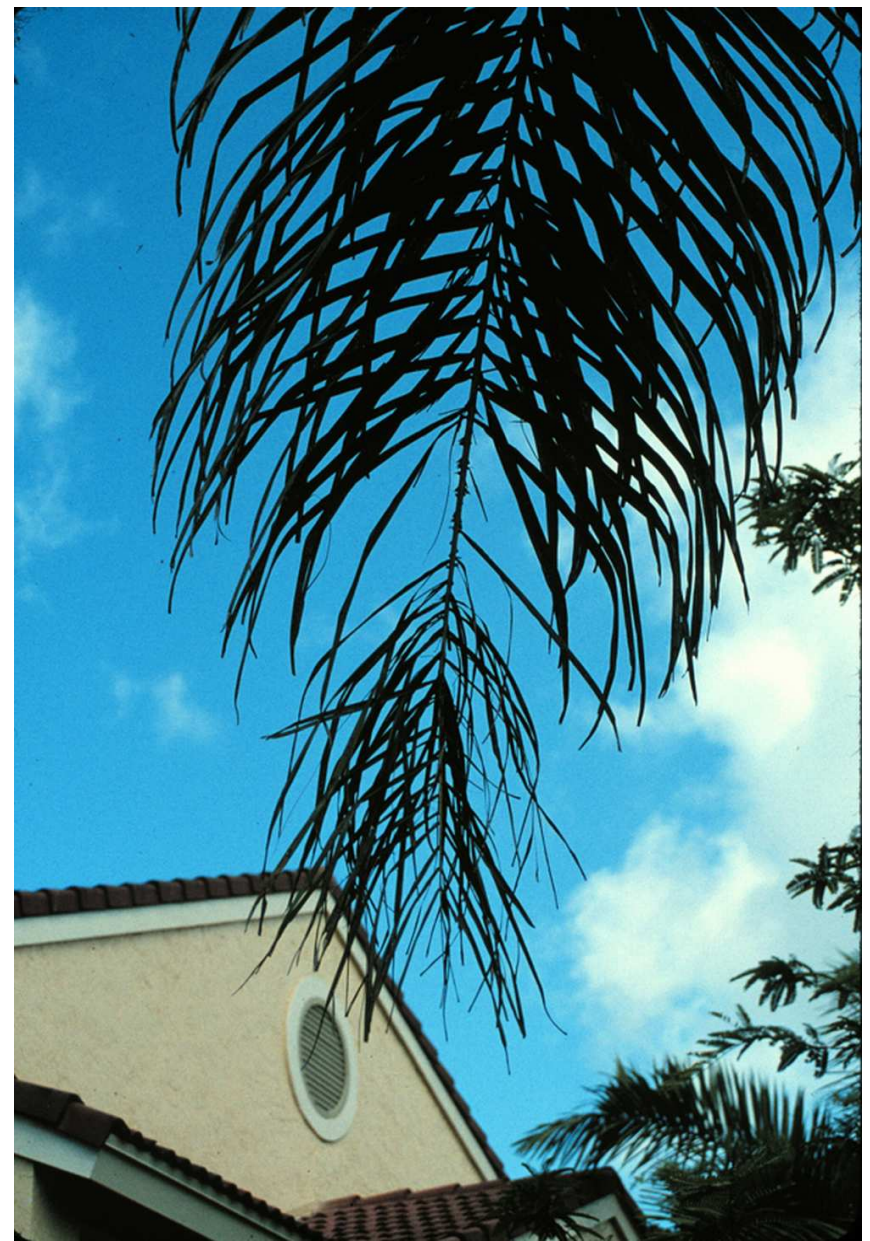

Figure 27. Small, thin leaflets at the tip of B-deficient Syagrus romanzoffiana new leaf. These leaflets are beginning to fall off. Credits: T.K. Broschat

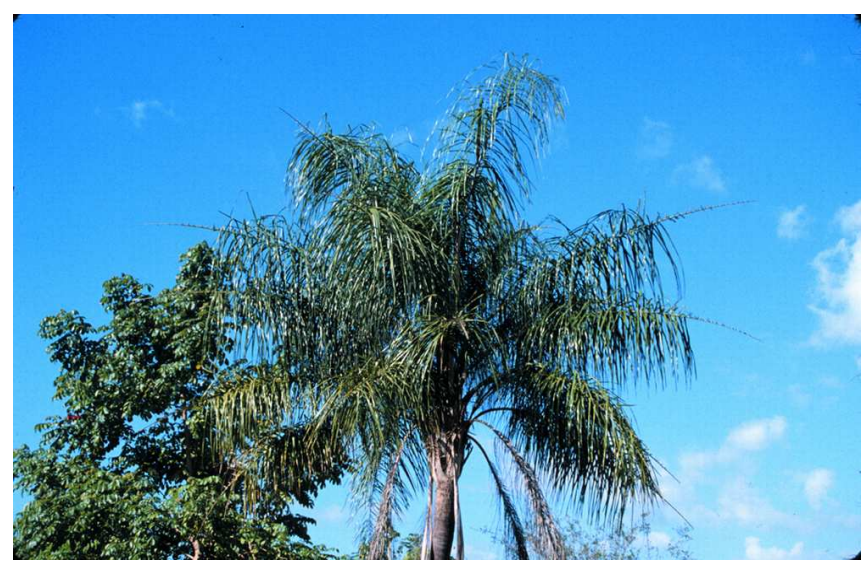

Figure 28. Bare leaf tips caused by chronic B deficiency in Syagrus romanzoffiana. Credits: T.K. Broschat

Boron deficiency can be very transient in nature, often affecting a developing leaf primordium for a very short period of time (e.g., 1 to 2 days). This temporary shortage of $\mathrm{B}$ can cause necrosis of the primordial spear leaf for a distance of about 1 to $2 \mathrm{~cm}$. 
When such leaves eventually expand, this "point" necrosis affects the tips of all leaflets intersected by that necrotic point, the net result being the appearance of a blunt, triangular truncation of the leaf tip (Figure 29). This pattern can be repeated several times during the development of a single leaf of Cocos nucifera (about 5 weeks) (Figure 30). Similar patterns have been observed in fan palms (Figure 31).

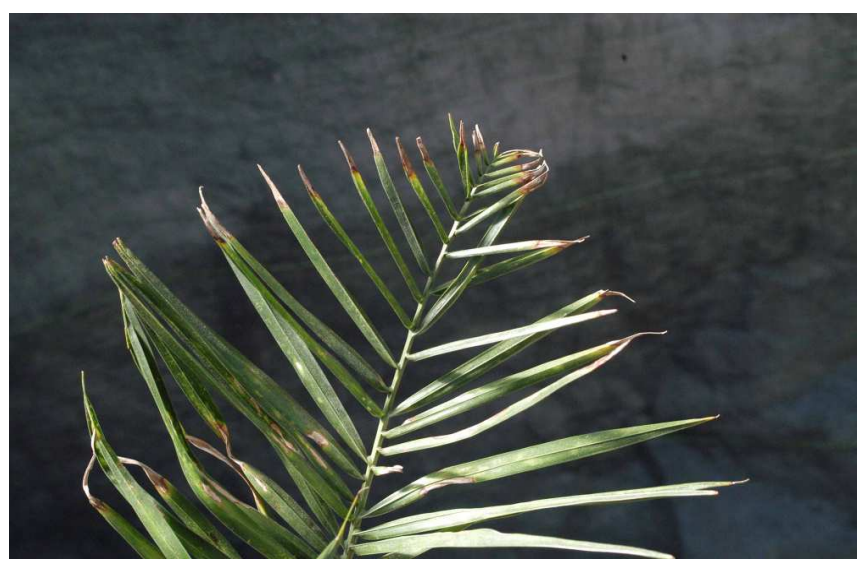

Figure 29. A temporary B deficiency can cause this inverted "V"-shaped leaf tip truncation. In this case the species is Phoenix roebelenii. Credits: T.K. Broschat

One of the most common symptoms of B deficiency is the failure of newly emerging spear leaves to open normally. They may be tightly fused throughout their entire length, or the fusion can be limited to basal or distal parts of the spear leaf. In a chronic state, multiple unopened spear leaves may be visible at the apex of the canopy (Figures 32 and 33).

Perhaps the most unusual symptoms of chronic B deficiency is the tendency for the entire crown to bend in one direction (Figure 34). This is one form of epinasty that can also cause twisting of petioles and leaves or sharp bends in the petiole, resulting in a new leaf growing downward along the trunk (Figures 35 and 36). These epinastic symptoms are believed to be caused by a B deficiency-induced decrease in IAA oxidase activity and therefore excessive auxin concentrations within the leaves.

Boron deficiency in its acute form produces yet other symptoms. Often leaves emerge greatly reduced in size and crumpled in a corrugated fashion (accordion-leaf) (Figures 37 and 38). Palms may grow out of these symptoms or the deficiency can kill the palm.

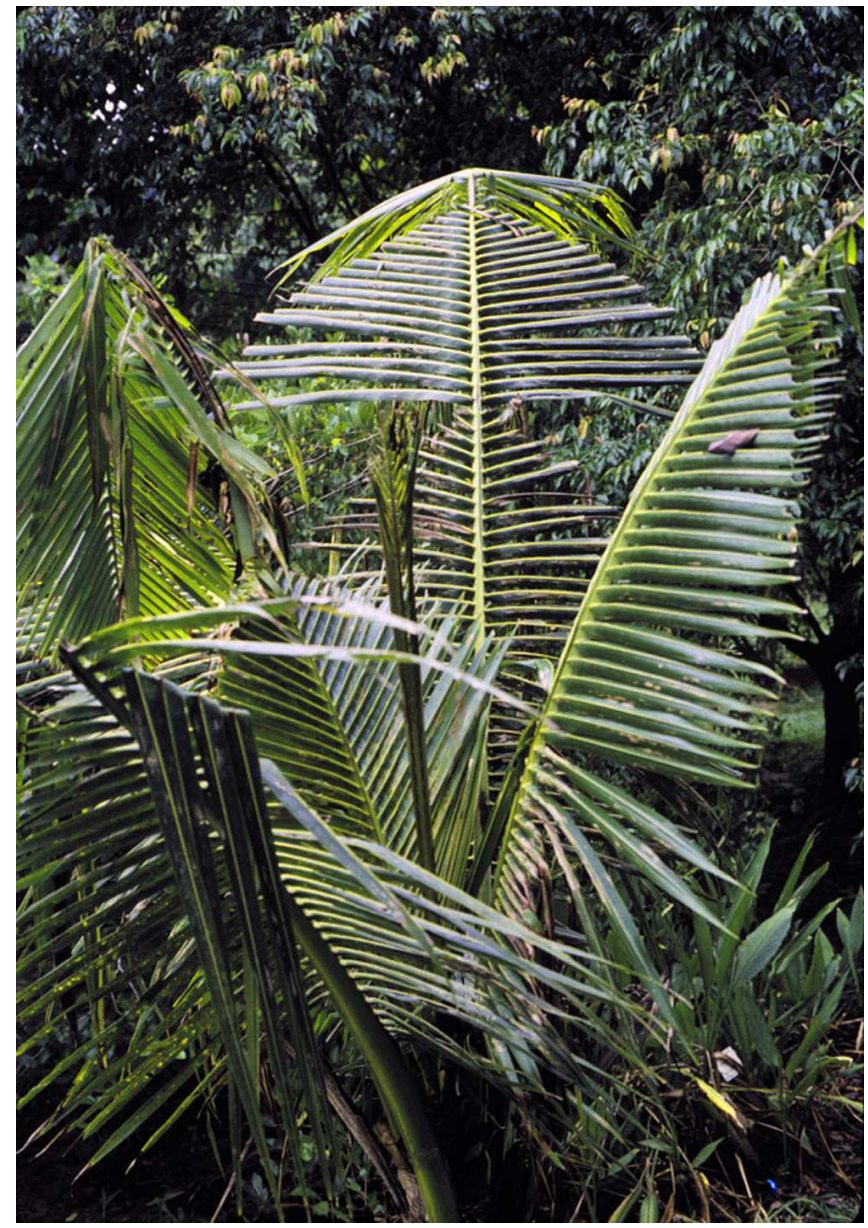

Figure 30. These Cocos nucifera leaves show the effects of a series of temporary B deficiency events, each causing an inverted "V" within the leaf. Credits: T.K. Broschat

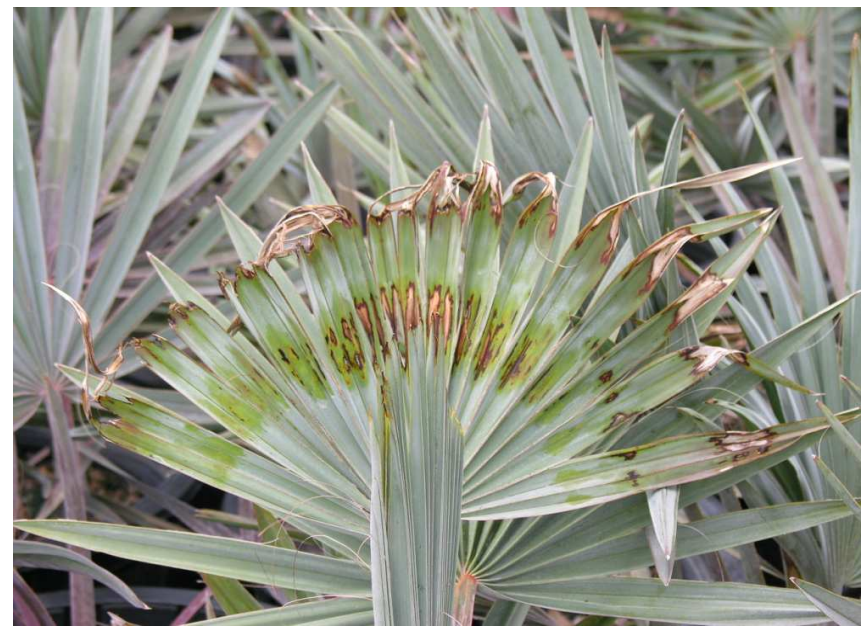

Figure 31. Boron deficiency of Bismarckia nobilis showing necrosis at two separate times during the development of this leaf. Credits: T.K. Broschat

Boron-deficient palms often abort their fruits prematurely and inflorescences (flowers) may have extensive necrosis near their tips (Figures 39 and 40). 


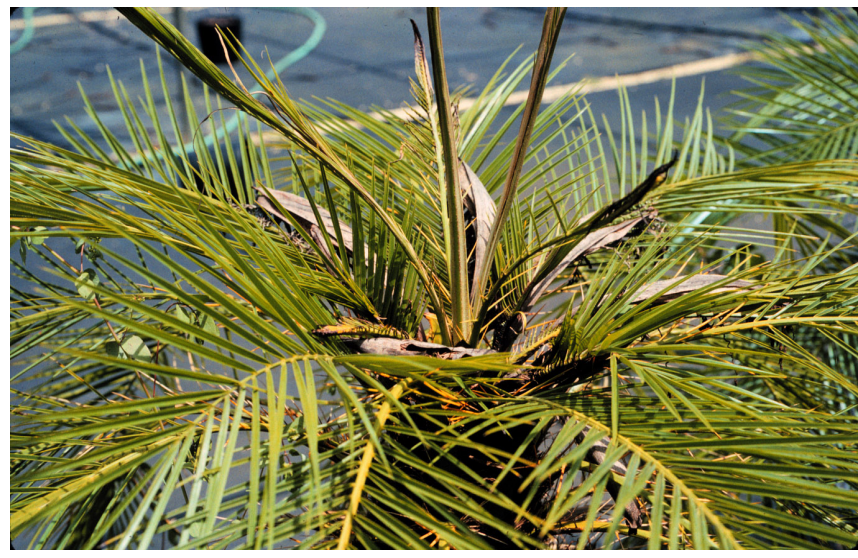

Figure 32. Multiple unopened spear leaves caused by B deficiency in Phoenix roebelenii. Credits: T.K. Broschat

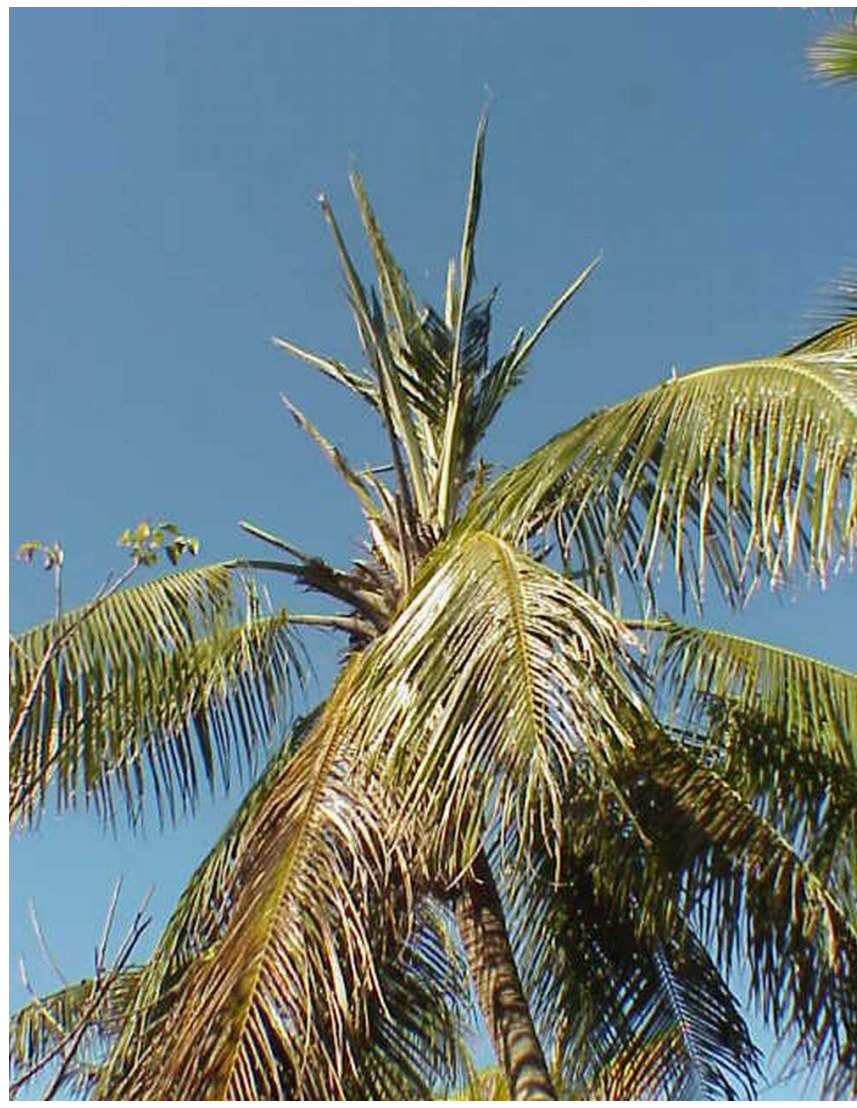

Figure 33. Severe B deficiency in Cocos nucifera, resulting in multiple unopened spear leaves. Credits: T.K. Broschat

These symptoms are very similar to those of lethal yellowing in species affected by that disease. The calyx end of fallen coconuts from LY-infected Cocos nucifera will be blackened, whereas coconuts from B-deficient trees will not have this blackened end (link to LY).

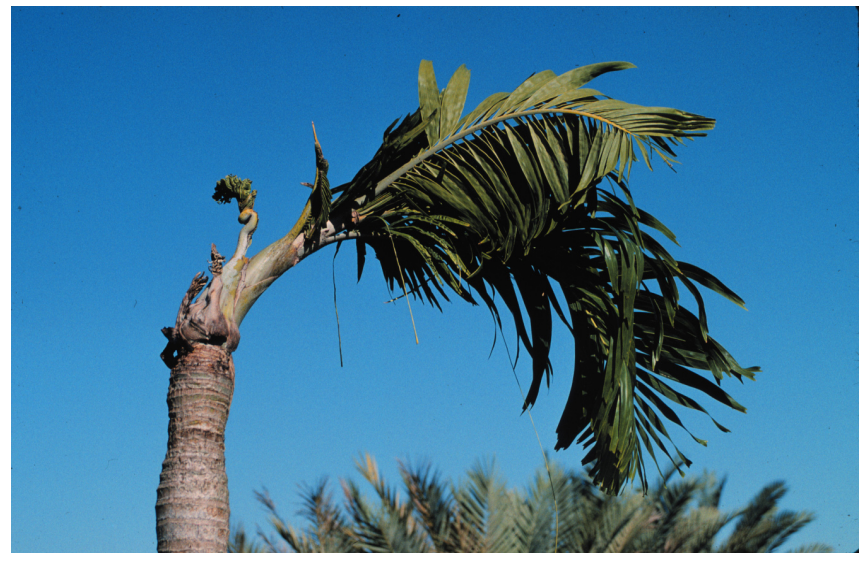

Figure 34. Boron deficiency in Adonidia merrillii (Christmas palm) showing sharp bending in the stem. Note that previous leaves were tiny indicating a temporarily acute B deficiency, but subsequent leaves were larger, suggesting the deficiency in now chronic. Credits: T.K. Broschat

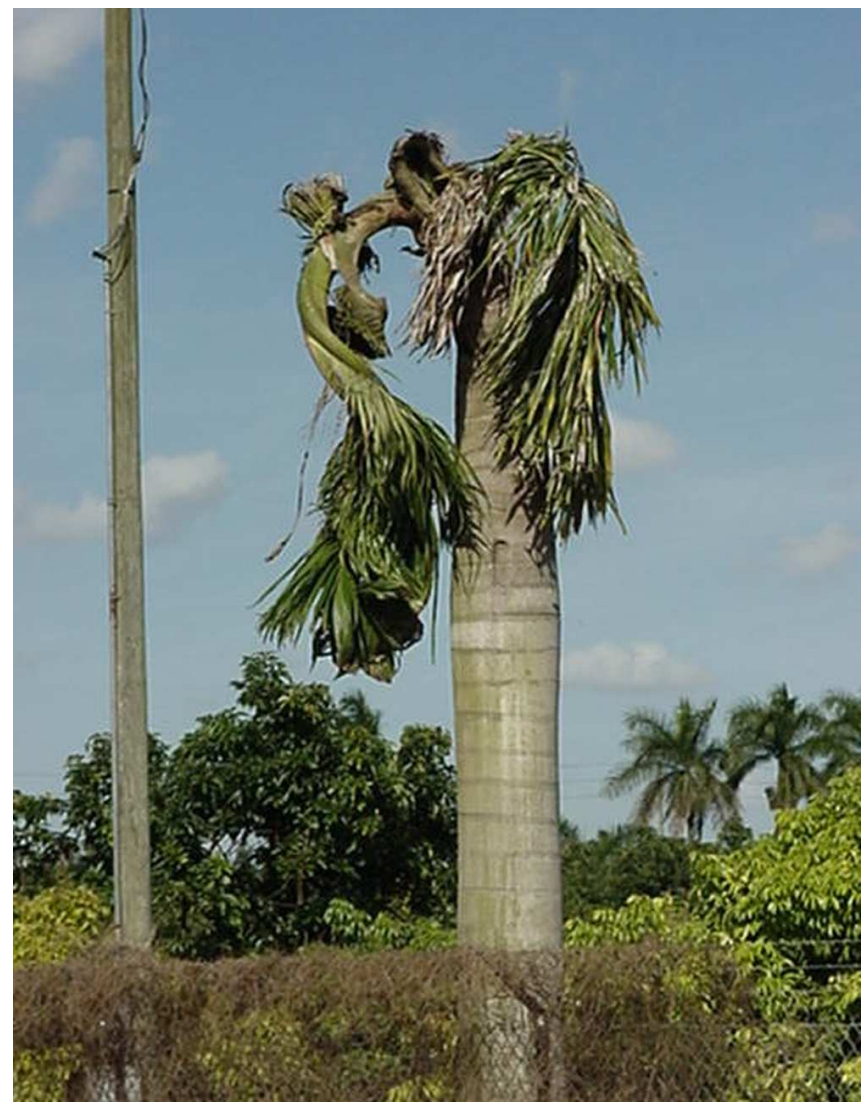

Figure 35. Severe B deficiency in Roystonea regia showing small leaves and severe epinasty. Credits: T.K. Broschat 


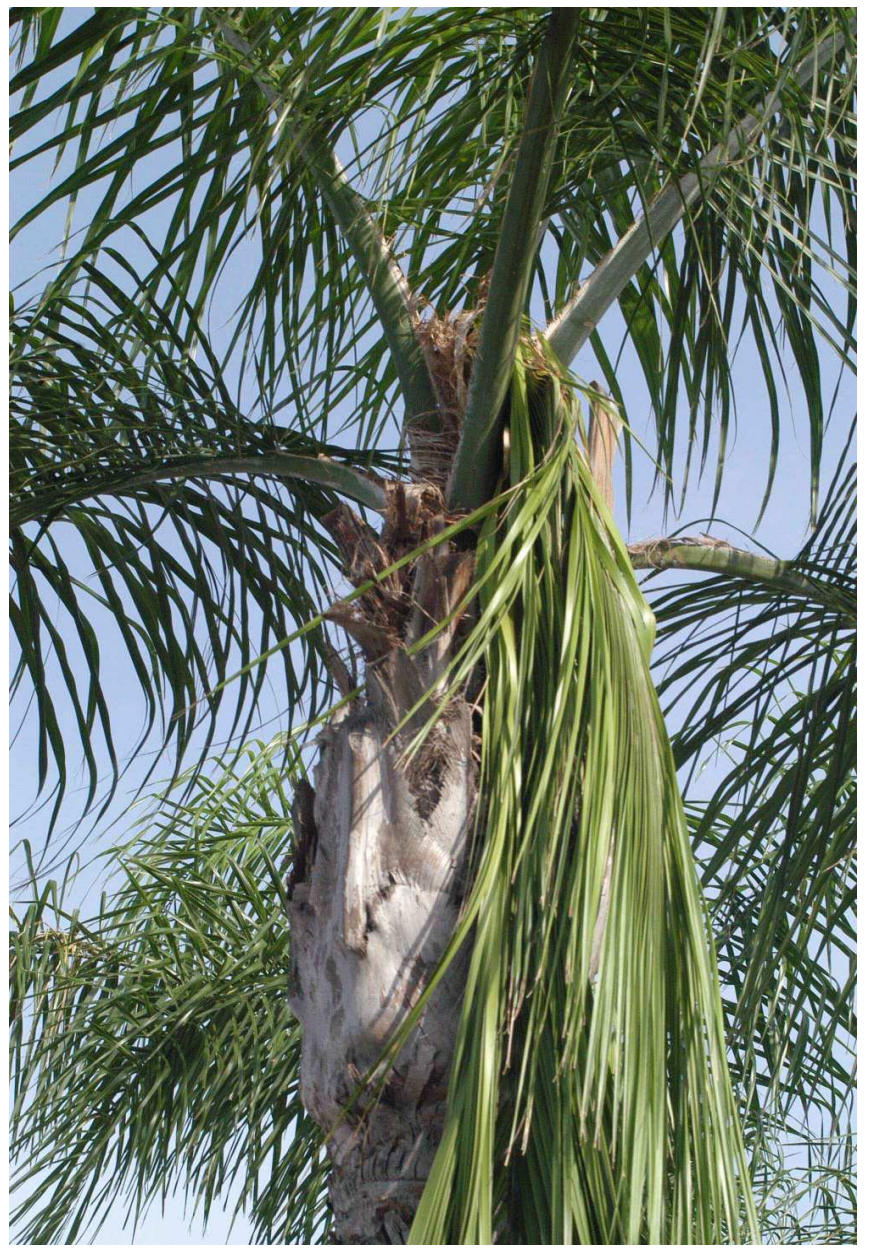

Figure 36. Boron deficiency in Syagrus romanzoffiana showing sharp bending in new leaf petiole. Credits: T.K. Broschat

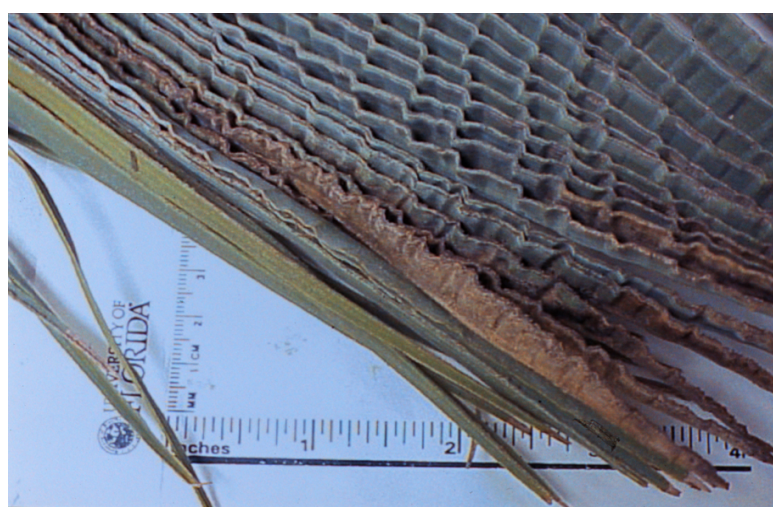

Figure 37. Accordion-leaf or mild B deficiency in Syagrus romanzoffiana. Credits: T.K. Broschat

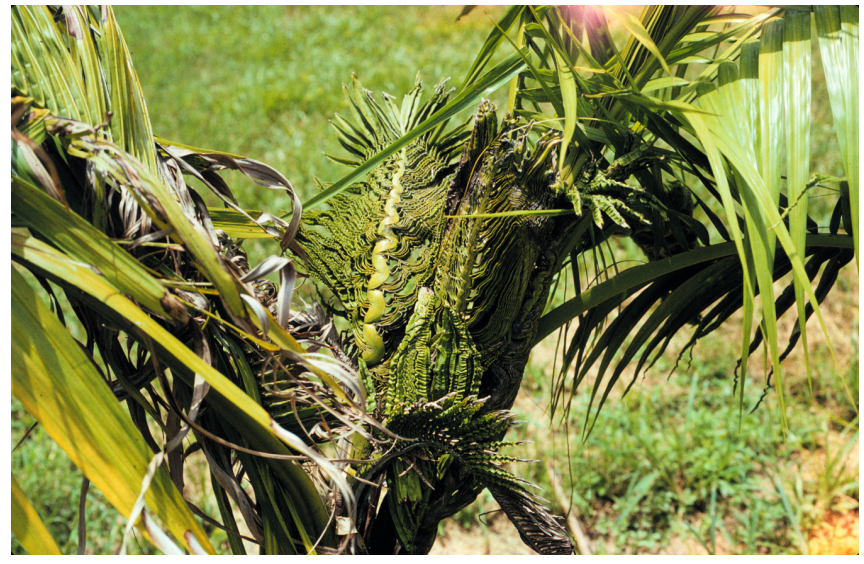

Figure 38. Severe B deficiency in Heterospathe elata (sagisi palm) showing small crumpled new leaves. Credits: T.K. Broschat

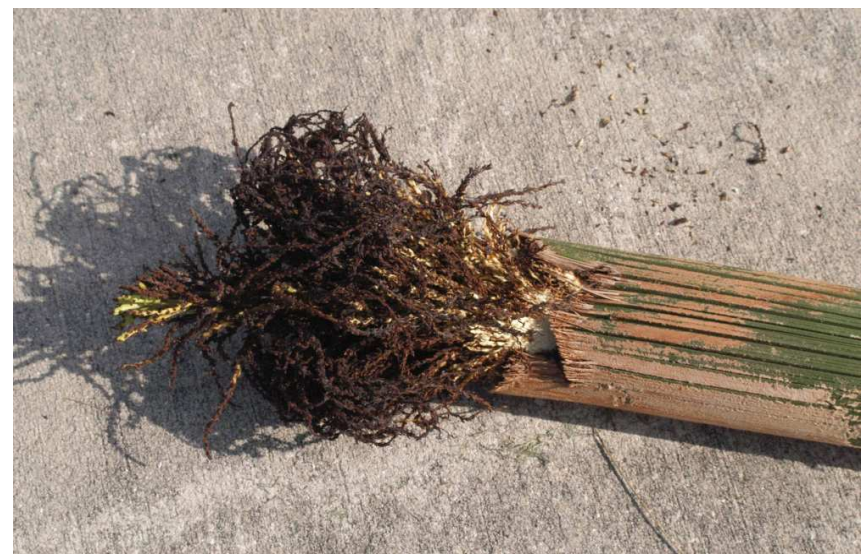

Figure 39. Necrotic inflorescence of B-deficient Syagrus romanzoffiana. Credits: T.K. Broschat

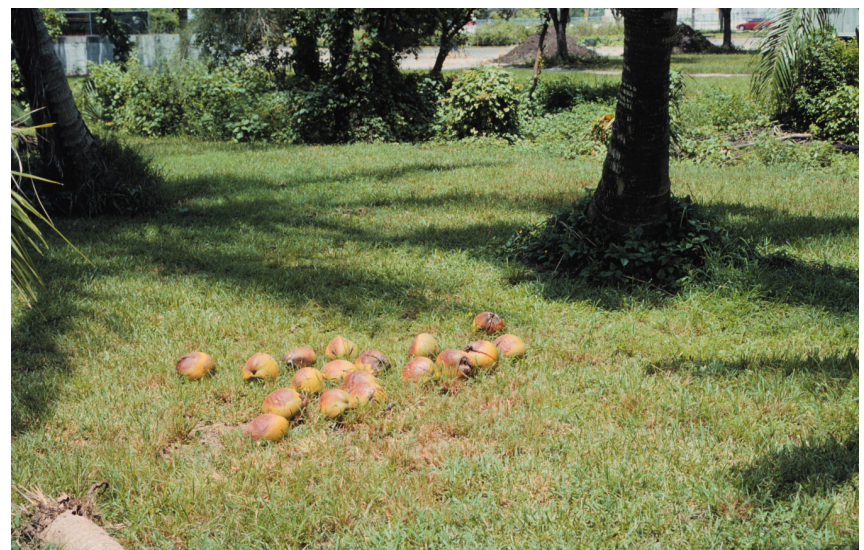

Figure 40. Premature fruit drop in Cocos nucifera caused by $\mathrm{B}$ deficiency. Credits: T.K.. Broschat 